\title{
MOVIMIENTO Y \\ CAMBIO EN MÉXICO Y AMÉRICA LATINA
}

Sergio Zermeño*

RESUMEN: En las sociedades aparecen constantemente la injusticia y la explotación, que inducen al conflicto. Sin detrimento de ello, en este artículo nos preguntamos cuál es la legitimidad de las posiciones que consideran que el único camino para cambiar la situación adversa y generadora de pobres es el de la confrontación y el anticapitalismo, o si, para mejorar la calidad de vida de nuestras sociedades, es necesario organizar y empoderar a los colectivos: generar el asociativismo y la conciencia del entorno en distintos espacios territoriales medios.

$$
\text { nose }
$$

ABSTRACT: In today's societies, we constantly find acts of injustice and exploitation leading to conflict. While not diminishing their importance, in this article, we will examine the legitimacy of the stances of those that think the only path to change the dire situations causing poverty is confrontation and anti-capitalism or that improving the quality of life in our societies entails organizing and empowering collective groups, promoting associativism and a broader awareness of different middle-range territorial units.

PALABRAS CLAVE: asociativismo, movimientos sociales, empoderamiento, confrontación, sedimentación.

KEY WORDS: associativism, social movements, empowerment, confrontation, sedimentation.

RECEPCIÓN: 22 de febrero de 2011.

APROBACIÓN: 24 de mayo de 2011.

* Instituto de Investigaciones Sociales, UNAM. 
CITAM Derechos Reservados.

La reproducción total o parcial de este artículo se podrá hacer si el ITAM otorga la autorización previamente por escrito. 


\section{MOVIMIENTO Y \\ CAMBIO EN MÉXICO Y AMÉRICA LATINA}

\section{Los movimientos sociales}

No cabe duda de que en referentes como "movilización social" o "movimientos sociales" se esconde una gama muy amplia y muy disímbola de manifestaciones colectivas. El movimiento estudiantil francés de mayo de 1968, y los otros movimientos estudiantiles que tuvieron lugar en aquellos años, son movilizaciones sociales; la enorme manifestación de mexicanos que impidió que el gobierno reprimiera el levantamiento zapatista en 1994, y aquella otra que en el 2005 impidió que el Jefe de Gobierno de la Ciudad de México, Andrés Manuel López Obrador, fuera destituido con base en artificios jurídicos, son movilizaciones sociales; lo son también los cerca de 30 mil micromovimientos, movimientos de base, grupos de acción social no partidista o grupos en movimiento que, según D. L. Sheth y Boaventura de Sousa Santos, ${ }^{1}$ pueden tener lugar simultáneamente en la India en torno a los aumentos de precios, salarios, salud, corrupción, etcétera; la definición de Alain Touraine ${ }^{2}$ de los movimientos sociales establece que éstos pasan por tres momentos, ejemplificados con la historia del movimiento obrero, que irían desde una etapa utópica, una radi-

${ }^{1}$ D. L. Sheth "Micromovimientos en la India: hacia una nueva política de la democracia participativa", en Boaventura de Sousa Santos, Democratizar la democracia. Los caminos de la democracia participativa, 2004, México, Fondo de Cultura Económica, p. 77-115.

${ }^{2}$ Alain Touraine, Production de la Société, 1973, Paris, Editions du Seuil, p. 542. 
cal y de pleno enfrentamiento y una de estabilización institucionalizante y de amenazas huelguísticas más propensas a la negociación que a la ruptura; también ejemplifica la diversidad de modalidades de la movilización social y las abismales diferencias e implicaciones que hay en cada una de ellas.

Nuestro objetivo en este ensayo es desentrañar dos concepciones que se encuentran amalgamadas en nuestros días, cuando se hace referencia a los movimientos sociales o a las movilizaciones sociales, particularmente en los países latinoamericanos y en los de desarrollo medio en general.

Por un lado, el altermundialismo como respuesta a la concentración del poder en gobiernos y empresas en nuestra época, ha construido un discurso bastante confrontacionista con base en la acumulación de las fuerzas globales de resistencia a la globalización. A continuación citamos algunos autores que ejemplifican esto:

Atilio Borón ${ }^{3}$ afirma que a partir de finales del siglo pasado se observa, en muchos países, una vigorosa recomposición del campo popular y una renovada militancia anticapitalista, cuyos inicios emblemáticos fueron la rebelión zapatista del 1o. de enero de 1994 y la así llamada "batalla de Seattle", en noviembre de 1999, que habrían de articularse globalmente a partir de la realización del primer Foro Social Mundial de Porto Alegre en enero del 2001 [...] poniendo de relieve el agotamiento del modelo neoliberal, tanto en el centro del sistema como en la periferia del mismo (respuesta a Halloway).

Emir Sader ${ }^{4}$ establece que la lucha por una nueva hegemonía derivará de una amplia alianza de todos los movimientos que se han congregado en el Foro Social Mundial de Porto Alegre, en toda su diversidad. Esa alianza requiere combinar el máximo de flexibilidad con algunos grados de centralización estratégica que permitan poner en práctica un

${ }^{3}$ Atilio Borón, “Poder, 'contrapoder' y 'antipoder’”, 2003, Bs.As., Herramienta, Debate sobre al libro Cambiar el mundo sin tomar el poder: el significado de la revolución hoy de John Halloway, disponible en, http://www.herramienta.com.ar/debate-sobre-cambiar-el-mundo/podercontra-poder-y-antipoder

${ }^{4}$ Emir Sader, "Las sorpresas de América Latina”, La Jornada, 27 de enero, 2007, disponible en, http:/www.jornada.unam.mx/2007/01/27/index.php?section= opinion\&article=032a1mun 
proceso de acumulación de fuerzas que va, de la fuerza social, moral, ideológica y teórica existente, a las fuerzas económica y política indispensables para que la construcción de un nuevo mundo -solidario, humanista, pacífico-sea realmente posible.

Daniel Bensaïd ${ }^{5}$ dice que apenas hay duda de que el levantamiento chiapaneco del 1o. de enero de 1994, "momento de nueva puesta en marcha de las fuerzas críticas", se incribe en el rebrote de resistencias a la mundialización liberal, confirmado desde Seattle a Génova, pasando por Porto Alegre. Ese momento es también el ground zéro de la estrategia, un momento de reflexión crítica (presentada por Marcos como una especie de tercera guerra mundial).

Guillermo Almeyra afirma que "así como el EZLN se apoyó en los movimientos indígenas y sociales anteriores en toda América Latina para su levantamiento en 1994 y, con éste dio nuevo impulso a las luchas subsiguientes; la experiencia de la APPO (Asamblea Popular de los Pueblos de Oaxaca), ha construido subjetividad, ha dado experiencias, y será un jalón en la lucha por próximas victorias [...] El socialismo no puede nacer y desarrollarse en un solo país, por grande y rico que sea, ni ver la luz en forma gradual y pacífica, sino que nacerá del conflicto social mundial prolongado". ${ }^{6}$

John Holloway considera que debe haber una acumulación de prácticas de auto-organización oposicional. El cambio de una política de organización (los partidos, el ejército revolucionario), a una de eventos que ya tiene lugar: mayo del 68, por supuesto, el colapso de los regímenes de Europa del este también; más recientemente, el desarrollo de la rebelión zapatista y la ola de demostraciones contra el neoliberalismo (Seattle, Davos, Washington, Praga, etcétera). ${ }^{7}$

${ }^{5}$ Daniel Bensaïd, “¿La revolución sin el poder?”, 2010, Argentina, debate sobre el libro Cambiar el mundo sin tomar el poder: el significado de la revolución hoy de John Halloway, disponible en, http://www.herramienta.com.ar/debate-sobre-cambiar-el-mundo/la-revolucion-sinel-poder

${ }^{6}$ Guillermo Almeyra, "De Oaxaca al mundo. APPO: Poder, revolución”, La Jornada Semanal, 14 de octubre, 2007, disponible en, http:/www.jornada.unam.mx/2007/10/14/semvigencia.html

${ }^{7}$ John Holloway, Cambiar el mundo sin tomar el poder: el significado de la revolución hoy, 2002, Buenos Aires, Universidad Autónoma de Puebla y Revista Herramienta. 
SERGIO ZERMEÑO

Raul Zibechi ${ }^{8}$ afirma que las experiencias de los aymaras bolivianos desde la guerra del agua de 2000, en Cochabamba, hasta las guerras del gas de 2003 y 2005 , fortalecen las esperanzas nacidas al calor de las insurrecciones populares de los últimos años en nuestro continente: derribaron dos gobiernos en veinte meses, crearon regiones fuera del control del Estado boliviano y deslegitimaron el modelo neoliberal.

\section{¿Sedimentación o discontinuidad?}

Por otro lado, a partir de estas afirmaciones, y sobre todo de la última, podemos plantear el problema, mostrar una acepción muy diferente de movilización social, cuando el propio Raúl Zibechi nos recuerda que:

En sus 27 años de existencia, los integrantes del Movimiento de los Sin Tierra (MST), en Brasil, fueron adaptándose a las diferentes coyunturas políticas, pero nunca dejaron de poner en el centro la ocupación de tierras, la producción y la educación, y fueron realizando una verdadera reforma agraria desde abajo. Hoy son medio millón de familias, 2 millones de personas en 5 mil asentamientos que ocupan 25 millones de hectáreas, en los que hay mil 500 escuelas. El MST cuenta con unos 15 mil militantes, tiene decenas de escuelas de formación y una universidad, la Escuela Florestán Fernández, y está siendo capaz de formar a sus propios especialistas y técnicos. En su quinto congreso, 40 por ciento de las delegadas eran mujeres [...] Se propusieron no sólo mantener la lucha contra el latifundio, sino buscar nuevas formas de lucha que se sitúen a la altura de los desafíos que están planteando el agronegocio y las trasnacionales. ${ }^{9}$

Noam Chomsky nos hace un planteamiento que coincide muy bien con lo dicho por Zibechi: él está absolutamente de acuerdo en que "el futuro de la humanidad depende de la resistencia a la globali-

${ }^{8}$ Raul Zibechi, "El Zapatismo y América Latina: profunda revolución cultural”, $L a$ Jornada, Perfil, 2 de enero, 2004, disponible en,http://www.jornada.unam.mx/2004/01/02/ per-raul.html

${ }^{9}$ Raul Zibechi, “Los sin tierra apuntan abajo y a la izquierda”, La Jornada, 29 de junio, 2007, disponible en, http://www.jornada.unam.mx/2007/06/29/index.php?section=opinion\& article $=024 \mathrm{a} 2 \mathrm{pol}$ 
zación", y hay acontecimientos esperanzadores, como la elección de Lula en Brasil: "lo que ocurrió ahí es asombroso y es una lección real a las democracias occidentales [...] Un movimiento popular, con bases de trabajadores, los Sin Tierra y muchos otros movimientos sociales lograron superar obstáculos tremendos, una alta concentración de capital, el odio de la comunidad financiera internacional, y eligieron a su propio presidente". ${ }^{10}$ Para Chomsky la resistencia a la globalización tiene un referente de larga sedimentación social basado en los movimientos y luchas que en el Brasil se han escenificado durante lustros.

En el mismo sentido y con las mismas implicaciones, en el libro Democratizar la democracia de Boaventura de Sousa, Patrick Heller y T. M. Thomas Isaac afirman que, a diferencia del resto de la India, "el éxito de las reformas agrarias de Kerala en la década de 1970, ampliamente conocidas por tratarse de la acción más trascendental y promotora de la equidad en el subcontinente, fue posible gracias al amplio apoyo de un movimiento campesino poderoso y a la exitosa campaña de alfabetización en masa de 1991 que señaló la importancia de movilizar a la iniciativa popular". ${ }^{11}$ De Sousa agrega que buena parte del éxito del presupuesto participativo en Porto Alegre y en Kerala se debe a un grado elevado de movilización social en la historia de esas regiones, y agrega que eso permitió llevar adelante la Campaña del Pueblo para la Planeación Descentralizada, la movilización "más radical y trascendente en este terreno emprendida en la India [...] un asalto frontal a feudos burocráticos del Estado y a las redes clientelares del sistema político: un gobierno estatal que lanza un movimiento para obligar a su propia mano a restructurar radicalmente el modo de gobierno". ${ }^{12}$

Este segundo grupo de acepciones de la movilización social en torno al presupuesto participativo, al Movimiento de los Sin Tierra y la reforma del rol del Estado en Kerala y en Portoalegre, están ligadas a una activación que lejos de provocar sólo la ruptura, desemboca esencialmente

${ }^{10}$ Noam Chomsky, "La alternativa decente", La Jornada, 1o. de febrero, 2002.

${ }^{11}$ Heller Patrick y Thomas Isaac T. M., "La política y el diseño institucional de la democracia participativa: lecciones de Kerala, India”, en Boaventura de Sousa, op. cit., p. 532 y 528.

${ }^{12}$ Op. cit., Patrick y Heller, p. 528. 
en el empoderamiento de la sociedad en paulatinos escenarios (continuidad) de concertación a lo largo de cada año, al grado de infundir una "mirada social" en el desempeño gubernamental (¿mandar obedeciendo?).

La pregunta sería si la referencia más adecuada a ese basamento debe hacerse en términos de confrontación o en términos de sedimentación, conscientes de que no hay una frontera clara; pero alguna diferencia hay, por ejemplo, entre la explosión, choque y muerte súbita de las acciones sociales en el México de los últimos diez años, por un lado, $\mathrm{y}$, por otro, la construcción asentada, paulatina y poco radicalizada de los barrios y asentamientos poblacionales de Porto Alegre, de otras ciudades brasileñas, de la lucha estable del sindicalismo en el ABC paulista, del Movimiento de los Sin Tierra, que a lo largo de muchos años han ido construyendo la base cívica que hoy les permite ejercer, en algunos puntos, el "presupuesto participativo" (sin que nada de esto quiera decir que su conflictividad en un momento dado no fue muy alta).

\section{La energía se dispersa}

En efecto, hay un asunto que comienza a ser preocupante en nuestro país: movimientos o luchas sociales que en los últimos quinquenios han surgido con gran vigor, que hasta un cierto punto han hecho imperar sus demandas y que han recibido el reconocimiento de la opinión pública, han terminado o están terminando abatidos por la represión gubernamental y en un gran desgaste; pierden aceleradamente apoyo ante el público amplio que les otorgó una legitimidad indiscutida y pierden también adeptos entre sus seguidores más cercanos.

El movimiento del Consejo Nacional de Huelga (CNH), en la UNAM, que durante 1999 movilizó a los universitarios y logró la hazaña de impedir, por tercera vez, que la educación en la universidad pública dejara de ser gratuita; el movimiento del Frente de Pueblos por la Defensa de la Tierra (FPDT), con su epicentro en San Salvador Atenco, logró revertir la injusta expropiación de sus tierras ejidales para que se construyera el nuevo aeropuerto de la Ciudad de México; el Movimiento de la 
APPO (Asamblea Popular de los Pueblos de Oaxaca) se nutrió de la organización popular y la activó irradiando su ejemplo en un amplio espacio territorial de aquella entidad; el movimiento del Ejército Zapatista de Liberación Nacional (EZLN) logró un reconocimiento y un apoyo casi unánimes en el interior y en el exterior del país; el Comité de Unidad Tepozteca (CUT) impidió el establecimiento de un club de golf, con su entorno inmobiliario y sus perniciosos efectos sobre los recursos hidráulicos de esa región.

El primero $(\mathrm{CNH})$ se enajenó a la amplia masa estudiantil debido a una radicalización excesiva y a la no aceptación de que debía terminarse la huelga una vez satisfechas las demandas; el segundo (Atenco), tampoco logró capitalizar su lucha con un mayor empoderamiento organizativo al conseguir la suspensión del decreto de expropiación y, al igual que el tercero y el último (la APPO y Tepoztlán), han terminado arrinconados como resultado de la confrontación y de la represión subsecuentes, y con una división severa de lo que alguna vez fueron sus sólidas bases de apoyo; el cuarto (EZ), ha perdido amplitud entre sus seguidores, sociales e intelectuales, y resintió una severa baja en su presencia mediática debido sin duda a un discurso y a una campaña que contrastan con lo que propuso en sus primeros diez años y que nos aturde con la insistencia de "derrocar pacíficamente" al gobierno, pero no nos dice cómo, ni qué proponer en su lugar; pero se debe también a su enfrentamiento sin sensibilidad a la campaña de López Obrador, al quererlo convertir en "el espejo de Salinas". En casi todos los casos la renuncia a hacerse cargo de las administraciones locales y el rechazo a aceptar fondos de los programas gubernamentales han conducido a que el PRI termine en los puestos ejecutivos y legislativos y disponiendo de los recursos públicos.

Lo que comienza a ser un problema y empieza a aparecer como una matriz del accionar de estas movilizaciones es que, pasada una primera etapa, llena de legitimidad y amplio apoyo por la justeza de sus demandas (educación gratuita, resistencia al despojo expropiatorio, dignidad y derechos para los pueblos indios), una primera etapa en donde se alcanzan logros destacables, en un segundo momento se cae 
en un desden evidente por las demandas resueltas y en un querer ir más adelante, a posiciones anticapitalistas porque, se argumenta, los acuerdos pactados no conducen a nada en el interior de este sistema. Lo anterior ha generado una deserción de sus actores solidarios y un empequeñecimiento concomitante de sus bases, una radicalización de su discurso en el sentido confrontacionista y un aislamiento sucesivo. Junto a ello, e inexplicablemente, esas dirigencias no quieren hacerse cargo de administrar a sus colectividades, como sí lo están haciendo en muchísimas partes de América Latina y del mundo, y el zapatismo, brincándose la evidencia de que sus Juntas de Buen Gobierno son gobiernos, le recomienda a todos los movimientos, en la Sexta Declaración de la Selva Lacandona, renunciar a administrar sus territorios y reprueba irreflexivamente las propuestas, como las de Armando Bartra, ${ }^{13}$ en el sentido de que las acciones pueden llevarse adelante con "un pie afuera y uno adentro" de las administraciones gubernamentales locales.

En efecto, incluso tomando en cuenta que la tendencia hacia la reducción de las masas movilizadas es una característica de todos los movimientos sociales, lo que parece, sin embargo, propio de las luchas a que nos estamos refiriendo es que a esa radicalización y a ese empequeñecimiento los acompañan inmediatamente un llamado a la "acumulación de fuerzas", un llamado hecho a todos los movimientos del mismo género a unirse contra un enemigo común, entendido como gobiernos, compañías trasnacionales, ricos, derecha, dominantes de cualquier tipo, policías de cualquier corporación. Así, el aislamiento se disimula cuando alguna situación extraordinaria de enfrentamiento o represión convoca a todas esas fuerzas en un mismo punto y abre el espejismo de un derrocamiento del orden establecido.

\section{La responsabilidad de los intelectuales}

Es obvio entonces que el objetivo mejor deseado de cualquier movilización debiera ser el mejoramiento de la calidad de vida vía el empode-

${ }^{13}$ Armando Bartra, “¡Caracoles! Descifrando la Tercera Estela”, Memoria, núm. 176, octubre, 2003, disponible en, http://www.revistamemoria.com/vista.php?id=2020\&path=fa $509 \mathrm{bb} 12 \mathrm{ebe} 7 \mathrm{fa} 6 \mathrm{af5f}$ 
ramiento de esos espacios sociales, su sedimentación y su continuidad, aunque todos estamos de acuerdo también en que las movilizaciones pueden terminar (o nacer) en el enfrentamiento, en la ruptura, en la represión y en la regresión organizativa y de la infraestructura productiva. Esto es lo propio de la acción social, pero ahora vamos a centrarnos en un asunto directamente asociado a éste, en el que los planos suelen confundirse: es el que tiene que ver con el discurso y con la intención de los actores intelectuales y políticos, al interpretar y tratar de inducir en un sentido o en otro a las movilizaciones.

El sub-comandante Marcos, a nombre del neozapatismo, ha empleado una serie de consignas, principalmente a raíz de la Sexta Declaración de la Selva Lacandona y de La Otra Campaña a partir del 2006, en torno a la movilización social y al cambio: "tumbar al supremo gobierno y a los ricos que lo están sosteniendo"; "el otro México que ya tomó la decisión de alzarse para derrocar a los malos gobiernos"; "se está gestando una rebelión, a veces espontánea, a veces organizada, contra la lógica del capital y la mercancía"; "queremos un mundo en donde quepan todos los mundos, incluso los ricos que en nuestro mundo tendrán un lugar... en la cárcel"; "ya estuvo bueno que estemos en nuestras casas (arengaba unos días antes de la brutal represión en Atenco), con el machete desenfundado, a ver a qué horas se le va a ocurrir a estos cabrones venir a robarnos. Mejor vamos a juntarnos y vamos por ellos. Vamos a derrocar a Zeferino, a Fox, al que esté arriba". 14 "El anticapitalismo del EZ es 'modesto', pero apunta al corazón mismo del sistema [...] la propiedad de los medios de producción" (en el arranque del "Segundo Encuentro de Zapatistas con los Pueblos del Mundo". ${ }^{15}$

Incluso dejando de lado la herencia mexicana, de confrontación ante el Estado fuerte (pre y post revolucionario), y de ausencia o de destrucción permanente de espacios de mediación, el planteamiento clásico de la guerra de movimientos, de la toma del Palacio de Invierno, es una propuesta altamente politizada, en el sentido de ir hacia el poder, hacia

${ }^{14}$ Marcos, "Presa La Parota "sólo podrá hacerse con una guerra en el sureste": Marcos", La Jornada, 17 de abril, 2006, disponible en, http://www.jornada.unam.mx/2006/04/17/index. php?section=politica\&article $=010 \mathrm{n} 1 \mathrm{pol}$

${ }^{15}$ Marcos, "Marcos: nuestro anticapitalismo es "modesto"”, La Jornada, 21 de julio, 2007, disponible en, http://www.jornada.unam.mx/2007/07/21/index.php?section=politica\& article $=008 \mathrm{n} 3 \mathrm{pol}$ 
la desestabilización, hacia el cambio repentino, el "derrocamiento", gracias a esa "acumulación de fuerzas", que cuesta trabajo pensar que será (o ha sido) pacífica (como ya el "68” y recientemente Las Truchas, Atenco y Oaxaca nos mostraron). Entonces, decir: "acumulemos fuerzas para derrocar al gobierno en nombre del pueblo", aunque se repudie a los partidos y a los puestos burocráticos, no es suficiente para borrar la evidencia de que estamos ante una manifestación fuertemente vertical, de poder (aunque viniera el derrocamiento y la primera fila de los movilizados no tomara las posiciones de mando, sabemos que entre las filas que siguen pululan los brazos de hierro).

\section{¿De qué cambio hablamos?}

Pero, ¿por qué el pensamiento confrontacionista y de guerra de movimientos sigue teniendo hoy una vigencia tan grande, al punto de haberse convertido en el planteamiento hegemónico en las movilizaciones de nuestro país y en los eventos del altermundialismo? Sin duda, en el caso mexicano, porque nuestra herencia de Estado fuerte hace que las luchas sociales adopten rápidamente la conformación piramidal del adversario a que se enfrentan y, en una especie de "lógica del suicida y del asesino", busquen a toda velocidad acumular fuerzas antes de ser barridos del escenario por la represión (nuestra herencia piramidal se reproduce como en espejo entre los movilizados y, al entrar en combinación con el verticalismo leninista de la toma del Palacio de Invierno, todo se encamina al choque). Pero a ello viene a unirse la evidencia, válida en el mundo entero, de una correlación entre fuerzas globales y fuerzas local-regionales que se encuentra cada vez más desproporcionada en detrimento de estas últimas y cunde la desesperación por cambiar las cosas de tajo ante este panorama de saqueo y explotación desenfrenados.

De esta manera, pensadores tan comprometidos con la reconstrucción de lo local y lo regional a partir de lo social, como Boaventura de Sousa, llega a escribir en su libro Democratizar la democracia:

Nuestra propuesta teórica se basa en la idea utópica de una exigencia radical: que sólo habrá emancipación social en la medida en que haya 
resistencia a todas las formas de poder. La hegemonía está hecha de todas ellas y sólo puede ser combatida si todas fueran combatidas de manera simultánea. Una estrategia exageradamente centrada en la lucha contra una forma de poder, pero tratando con negligencia todas las otras, puede, por más nobles que sean las intenciones de los activistas, contribuir a profundizar en vez de atenuar el fardo global de la opresión que los grupos sociales subalternos cargan cotidianamente. ${ }^{16}$

Sin duda, Adolfo Gilly expresa esto de una manera más cruda al comentar el libro de John Holloway, Cambiar el mundo sin tomar el poder: "El marxismo es la teoría del no, de la negación, de la lucha por lo que no es y será porque quiere ser. Es la teoría del conflicto: no de su solución, sino de su persistencia en la vida y en la historia. El marxismo es una teoría de la dominación (fetichizada), de la explotación (objetivada), de la revolución (organizada) y de la liberación (en la comunidad real y ya no más ilusoria)" ${ }^{17}$

Los movimientos altermundialistas en los distintos puntos del orbe han demostrado una gran virulencia; en ellos se congregan poderosos sindicatos como el americano de la AFL-CIO, agrupaciones ecologistas como Green Peace, de género como el movimiento gay y lésbico, organizaciones campesinas, grupos indígenas y religiosos, misioneros, anarquistas, defensores de los derechos del hombre, de los consumidores, etc. Pero no cabe duda que, en su gran mayoría, los participantes en estas manifestaciones terminan muy lejos de los espacios cotidianos en que se desenvuelve la vida de los excluidos, en nombre de la que esos mismos movimientos hablan, y algo más definitorio, esos movimientos tienen muy poca incidencia para modificar los términos en que se desenvuelven esas vidas (son espacios, sin embargo, en los que puede desarrollarse un gran protagonismo cultural y político, pero ésta es una lógica que poco tiene que ver con el empoderamiento de lo social circunscrito). Se producen líderes, obras de arte, material fílmico, fotográfico,

${ }^{16} \mathrm{Op}$. cit.

${ }^{17}$ Adolfo Gilly, "El hacedor", 2002, México, en debate sobre al libro Cambiar el mundo sin tomar el poder: el significado de la revolución hoy de John Halloway, disponible en, http://www.herramienta.com.ar/debate-sobre-cambiar-el-mundo/el-hacedor 
plástico, periodístico, literario, etc., pero es demencial la velocidad con que esos productos se elevan al nivel del consumo del mundo de la integración y se separan de las necesidades por ellos evocadas.

Igualmente, es un hecho que desde lo local regional tampoco es posible luchar contra la dominación que establecen los grandes poderes trasnacionales, desde los organismos financieros hasta los ejércitos de las potencias mundiales, pasando por el poder sin contrapeso de los grandes consorcios del globo: no basta sólo con empoderar a lo local-regional. Pero sea como sea, lo cierto es que sin el empoderamiento de la sociedad civil, de lo social mismo, cualquiera de esas batallas estará perdida de antemano y cualquier reblandecimiento o crisis de la dominación global no podría ser aprovechado para mejorar la condición de la gente.

Nadie duda de que la movilización puede devenir, y en muchos casos así sucede, en sedimentación democrática, en empoderamiento social, pero en una importante vertiente del pensamiento social y de la opinión pública la movilización se confunde con el cambio en el corto plazo y, en muchos casos, con el cambio radical (que es con mucho la imagen clásica de la revolución y, hoy, de las confrontaciones altermundialistas). El camino es largo y es más social que político, porque con la desestabilización se da pie al desmantelamiento.

\section{Las vías de la construcción social}

Es necesario detenernos un poco en esta idea, según la cual, los cambios cualitativos -los que realmente conducen a un estadio nuevo-se deben generar por la vía del conflicto, del enfrentamiento de los contrarios, de los movimientos y las luchas sociales; es más, de la confrontación anticapitalista (altermundialista, anti-monopolista, anti-global); una propuesta que implica que, únicamente por medio del debilitamiento o desaparición del adversario de la escena social (aristocracia, oligarquía, burguesías...) se alcanzaría el mejoramiento de la calidad de vida de los amplios agregados sociales. 
Las vías de la densificación de lo social han sido múltiples, como lo han demostrado Barrington Moore Jr., ${ }^{18}$ Eric Hobsbawm, ${ }^{19}$ Antonio Gramsci, ${ }^{20}$ Theda Scokpol, ${ }^{21}$ Robert Putnam ${ }^{22}$ y otros. La violencia de la Revolución francesa contrasta con lo terso que fue para Inglaterra el pasaje desde la sociedad campesina hasta la moderna sociedad industrial y la adaptación de su aristocracia al mundo industrial moderno (lo que no niega que hubo, aquí y allá, violentas luchas campesinas, obreras y populares), y lo mismo puede decirse del Japón y de la India.

En América Latina nos alimentamos de una tradición que privilegió a lo jacobino, a lo bolchevique, al ejército popular, al foco guerrillero, sin analizar todos los ejemplos de empoderamiento social por la vía paulatina, y confundimos a las guerras mundiales, en el este europeo, con procesos revolucionarios de confrontación de clases y de cambios cualitativos que dejaban atrás a las sociedades jerárquicas y nobiliarias. Pero nunca quisimos aceptar que las aristocracias y las burguesías podían constituirse, con el paso del tiempo, en agentes densificadores de lo social, al igual que muchos agregados de las clases laborales y de los servicios (la época dorada del sindicalismo y del fordismo pareció una claudicación).

Nunca aceptamos que, al igual que Inglaterra, muchas regiones europeas y de ultramar, transitaron a la modernidad sin grandes sobresaltos; tampoco meditamos suficientemente en el hecho de que países que sí se vieron divididos violentamente, como España y como el propio México, habrían podido acceder al mundo industrializado y hubieran podido modernizarse sin los terribles sufrimientos de las guerras fratricidas (desórdenes y alteraciones que en la mayoría de los casos retrasaron este tránsito, debido a la destrucción tremenda de los espacios, procesos y agentes generadores de energía).

${ }^{18}$ Barrington Moore Jr., Los orígenes sociales de la dictadura y de la democracia. El señor y el campesino en la formación del mundo moderno, 1973, Barcelona, Península.

${ }^{19}$ Eric Hobsbawm, En torno a los orígenes de la revolución industrial, 1971, México, Siglo XXI.

${ }^{20}$ Antonio Gramsci, "Paso de la guerra de movimiento y del ataque frontal a la guerra de posición”, Cuadernos de la Cárcel, núm. 6, 1943.

${ }^{21}$ Theda Scokpol, States and Social Revolutions: A Comparative Analysis of France, Russia, and China, 1979, New York, Cambridge University Press.

${ }^{22}$ Robert Putnam, Making Democracy Work, Civic Traditions in Modern Italy, 1993, New Jersey, Princeton University Press. 
Se asegura entonces que, sin tales cataclismos, nunca nos habríamos librado de las oligarquías y de los despotismos. Pero eso es muy relativo si miramos la condición descendente que esos actores premodernos ocuparon en regiones del mundo que no pasaron por grandes eventos revolucionarios (la España de hoy, que perdió una revolución y transitó por cuatro décadas de dictadura, no parece estar menos acoplada a la modernidad que muchas sociedades europeas en donde las fuerzas revolucionarias anticapitalistas se impusieron en la Europa Central y del Este).

Es más, España se encuentra hoy en un nivel de modernidad que la acerca cada vez más a los altos estándares de vida del resto de la Unión Europea, a pesar de que las fuerzas más conservadoras se impusieron en la confrontación armada (la aristocracia al frente), mientras que México, que por la fuerza del estallido social suprimió a la casta terrateniente y colocó en la dirección nacional a una élite dirigente y triunfante, parece des-modernizarse (des-densificarse) con gran celeridad.

Más bien lo que debería llamar nuestra atención es la manera acrítica por la que infinidad de pensadores latinoamericanos y de muchas otras latitudes pasaron de la formación marxista revolucionaria a la aceptación de que el cambio podría hacerse a partir de las instituciones del tránsito a la democracia, "barriendo las escaleras de arriba para abajo" y olvidándose, aquí sí de manera alarmante, del imperativo que establece que sin una sociedad fortalecida, sin densificación de lo social, no hay bondad institucional y reformas de buena fe, sino acaparamiento de los bienes sociales, saqueo, corrupción, manipulación desde los medios de comunicación, sobre todo electrónicos, imposición en la que participan por igual gobiernos y partidos de izquierda y derecha, tal y como se está viviendo en México en esta integración de mercados abiertos y globalización salvaje.

La idea de que sólo con rupturas bruscas del orden y con la anulación de las fuerzas dominantes es posible densificar a lo social y mejorar la calidad de vida de sus integrantes ha demostrado ser falsa tanto en el capitalismo industrial como en la era neoliberal. Pero aclaremos 
que eso no quiere decir que la violencia y la confrontación son evitables, pues es obvio que en ciertas condiciones de explotación y saqueo las explosiones sociales se generan de manera espontánea, porque entre otras cosas no es un asunto de conocimiento de la historia por parte de los actores que rompen el pacto social.

Sin embargo, en las últimas movilizaciones que han tenido lugar en nuestro país (el neo-zapatismo, Tepoztlán, Atenco, el Consejo General de Huelga en la UNAM a partir del movimiento de 1999, el movimiento de la APPO en Oaxaca), y también en la mayoría de las anteriores movilizaciones (el 68 en primerísimo lugar), la cultura intelectual que ha imperado entre las dirigencias y entre las bases movilizadas ha sido una que privilegia la radicalización, la ruptura, la acumulación de fuerzas y que considera claudicante la negociación: avanzar (derrocar), para consolidar, antes que consolidar (a los cuerpos sociales embarnecidos por la movilización), para de esa manera avanzar.

Regresando entonces a nuestro planteamiento, vemos que no tiene fundamento la afirmación que establece que intentar la reconstrucción social en regiones medias por la vía del mejoramiento paulatino de las condiciones de vida es un reformismo inaceptable, una especie de bálsamo para los sufrimientos inmisericordes de la globalización y que solamente con medidas radicales y anticapitalistas puede plantearse de manera realista esa reconstrucción. Hay que aceptar que las vías de la violencia y la confrontación son inevitables en ciertas condiciones, lo que no quita que, a partir de esas rupturas (o sin ellas), haya una infinidad de otras vías posibles en la búsqueda de la densificación social y el mejoramiento de la calidad de vida de las colectividades.

\section{La concepción del cambio en lo social}

Llegamos al punto central: la concepción del cambio, el orden social deseado y el lugar en donde se encuentran los elementos para acercarnos a su consecución. Digamos a este respecto que la flecha del tiempo es un hecho indiscutible, pero: ¿está siempre ligada a la evolución 
cuando tratamos de la sociedad?, ¿al postulado de la modernidad que nos impuso que después de una etapa viene otra etapa, posterior, superior y mejor?

Depende; si hablamos de la evolución biológica no cabe duda, pero también, si lo vemos a lo largo de diez siglos, la flecha del tiempo ha sido inobjetable en lo que respecta al dominio de la técnica sobre el medio natural, con el espectacular ejemplo de la medicina; inobjetable en relación con la secularización, es decir, a la minimización de los referentes religiosos y mágicos en el quehacer de los individuos y las colectividades; ha sido inobjetable en lo que toca a la minimización del poder despótico y al fortalecimiento de los agentes de la sociedad civil, etcétera.

Pero, sin duda, en este último aspecto, la interpretación de esta linealidad ha dejado mucho que desear: las sociedades que más se han empoderado frente a sus agentes estatales, políticos, señoriales y del gran capital han sido las occidentales, con todo y sus enclaves llamados de ultramar. Y aquí justamente surge, a lo largo del proceso de modernización, la idea de que la etapa del capitalismo debería ser sustituida por otra etapa, superior y mejor que fue llamada socialista o comunista para acentuar la fuerza de los actores organizados desde lo social frente al Estado y frente a los poderes de la burguesía capitalista. A esa idea de la modernidad se le asoció con el cambio inducido, de manera tal que el proceso de pasaje a lo nuevo fuera más rápido (científicamente diseñado, si se quiere). Entonces, se asoció a esta concepción las ideas de revolución y de anticapitalismo.

En realidad se estaban confundiendo dos cosas: fortalecimiento de la sociedad, con anulación del sistema burgués. Realmente quienes habían fortalecido más a la sociedad habían sido primero algunas aristocracias modernizadoras, después, o paralelamente, las burguesías, y en fin, el proletariado con su acción sindical y partidista.

Entonces se pensó que había que quitar definitivamente del mapa a los lastres, que era sin duda la burguesía, que impedía una socialización completa, un empoderamiento completo de la sociedad y, pasado un tiempo, también habría que anular al Estado, que impedía igual- 
mente esa socialización, ese empoderamiento, esa densificación de lo social.

Para el establecimiento de ese nuevo orden, de esa nueva etapa, era indispensable una fuerza reordenadora (por lo menos transitoriamente se asumía), y entonces surgieron los ejes duros del partido, la dictadura del proletariado, el Soviet Supremo, el puñado de dirigentes iluminados, conciencia exterior a la masa que la guía hacia el nuevo estadio, apoderándose de la conducción del aparato estatal. Era evidente que se había cometido un gran error de apreciación: con el odio a la burguesía se confundió el odio a todos los agentes sociales que pudieran implicar una resistencia al nuevo proyecto, a la nueva dirigencia, a la nueva burocracia estatal, al nuevo Estado.

Todas las corrientes socialistas y marxistas perdieron en el camino, o de plano minimizaron hasta desaparecerla, la idea más importante legada por la historia de las sociedades y puesta enfrente de los ojos de todo mundo, ya con la sociedad industrial de Occidente: la importancia de los actores dinámicos densificados a lo largo de muchos siglos, como terminaron siendo la burguesía y el proletariado, las aristocracias modernizadoras y las clases medias, asociadas al componente de la cultura y la educación universitaria. Digamos que las corrientes marxistas y socialistas burocratizaron a la idea de orden social en lugar de socializarla.

Pero no nada más del lado del pensamiento socialista se minimizó el principio de la densidad o densificación de la sociedad como elemento clave para alcanzar el buen orden del futuro. Del lado del pensamiento liberal se acometieron igualmente, al menos, dos impulsos que obscurecieron el hallazgo de la densificación social, el más importante que la sociedad occidental nos había puesto ante los ojos.

Primeramente, el culto a la democracia representativa, a la idea de que lo que había que fortalecer ante todo, ante lo social y ante lo estatal, era un espacio de concurrencia de actores que por medio de partidos y organizaciones políticas representaran al resto de los agregados e individuos de cada colectividad y que, a partir de los acuerdos que ahí se lograran, el buen orden, hacia arriba o hacia abajo, quedaría asegu- 
rado. En muchos momentos, pero particularmente en el tiempo presente, estamos sufriendo las consecuencias de haber llevado al extremo esta idea de que "las escaleras se barren de arriba para abajo", particularmente con las teorías del nuevo institucionalismo y de la tercera ola de democratización, de tránsito a la democracia.

El segundo gran influjo que desvió nuestra mirada del hallazgo central de la densificación social, vino por el lado de la carrera desenfrenada y ya sin orientación alguna, encarnada en el avance científicotécnico; la idea cuyos postulados se cumplen cada vez menos, pero que permanece como una ideología vigente, que asegura que los científicos, las universidades y los aparatos del saber y de la técnica encontrarán una solución para cada problema y encontrarán un orden nuevo, superior y mejor, para que vivamos más felices.

El punto, en resumen, es que ninguna de las dos grandes corrientes de la modernidad pudieron ver lo que estaba en la base de sus querellas: la burguesía, en efecto fue defendida por el liberalismo como el actor emprendedor, dinámico, pero predominó como agente económico, y con el advenimiento de los monopolios quedó oculta su función, que había sido la del más poderoso de los densificadores sociales; el proceso de acumulación monopolista se dio como un fenómeno inevitable y la figura del burgués, gracias en mucho a la crítica socialista, se perdió mezclada con la figura de la gran empresa primero, y de la corporación financiera más tarde, de manera que se volvió muy práctico el empleo del calificativo anti-capitalista, con el cual fueron confundidas todas estas modalidades de lo burgués.

A partir de esto, podemos argumentar que la flecha del tiempo no tiene una trayectoria lineal progresiva cuando hablamos de la dinámica social (aunque, por lo visto, tampoco en las ciencias duras, en la química, por ejemplo), sino que puede tener un desempeño de movimiento hacia adentro, hacia ella misma, un movimiento de sedimentación de A, que no irá en el sentido de un pasaje de A hacia B. Si las ciencias sociales y las ciencias del hombre hubieran evidenciado lo que tenían enfrente en la era moderna, es decir, la sedimentación de los actores sociales, individuales y colectivos, no hubieran invertido 
todas sus preocupaciones en la acumulación y la gran empresa, en el desarrollo desenfrenado de la ciencia y la técnica, en la urgencia anticapitalista por destruir esto y pasar a un nuevo estadio, porque en realidad la materia con que debió haberse construido ese nuevo mundo se encontraba en un alto grado presente, y a punto de debilitarse, en esa misma sociedad occidental, en ese mismo estadio.

¿Pero cómo se hubiera logrado que ese empoderamiento y esa densificación de actores individuales y colectivos imperara sobre las tendencias "naturales" de la acumulación del capital y de la concentración del poder estatal que acompañó la consolidación de los estados nacionales? En realidad, era imposible que esto se hubiera convertido en una guía de acción en los siglos XVIII o XIX, en una ideología o una cultura de la densificación social. El inicio de las sociedades industriales de Occidente se dio en un espacio demasiado desigual en su interior y hacia el exterior; nada podía convencer a esos agentes sociales y estatales de que era mejor una especie de ciudades estado, sedimentar espacios sociales en donde sus ocupantes fueran poco a poco viviendo mejor, educándose mejor, siendo más solidarios entre sí, etcétera, en lugar de lanzarse a las grandes concentraciones industriales y a las grandes aventuras imperialistas. Y no era posible, entre otras cosas, porque el dejar atrás el mundo del medioevo, los señoríos y los poderes despóticos, se logró bajo una velocidad tremenda del desarrollo de los transportes, las industrias y la vida urbana (en medio de esa vorágine tienen lugar todas las discusiones de la Internacional socialista entre la reforma o la revolución, la toma del Palacio de Invierno o los pequeños pasos, pero, como sabemos el bolchevismo le dio una patada al tablero y esa discusión tan rica de la concepción del cambio fue prácticamente enterrada).

Sin embargo las cosas han cambiado. En este momento en que el entorno natural se encuentra al borde del desequilibrio catastrófico, en que la industria y las finanzas se desempeñan en la más evidente irracionalidad, en que las grandes potencias aplastan sin misericordia a los colectivos que se interponen en sus proyectos de energía y seguridad, en que la mayoría de las áreas de la ciencia y de la técnica han 
tomado unas dinámicas que poco se preocupan por la felicidad de las personas, en este que es nuestro momento, repetimos, el dar visibilidad nuevamente al referente de la densificación de los colectivos en el plano de lo social se vuelve una necesidad imperiosa.

Digamos que las sociedades más avanzadas lo están llevando a cabo en muchos de sus espacios interiores, si bien la ideología que aún predomina en ellas, por su propia conveniencia, es la de los mercados abiertos, la de los campos y los galerones de la maquila, campos de la muerte, la de las grandes corporaciones industrial-financieras y la del control militar de sus abastecimientos. Atestiguamos, en efecto, la forma cuidadosa en que se está organizando la vida en los barrios de París, de Barcelona, de Berlín, al cuidado ecológico con que se producen las legumbres y los alimentos cárnicos, a la recuperación de los ríos y las cuencas en esas partes del mundo, a la elevación de la conciencia de quienes los habitan y de sus organizaciones sobre su entorno vital, a la educación ambiental.

Así que puede haber una o muchas flechas del tiempo, pero la que verdaderamente importa para la superación humana es una que parece ya no viajar tan rápido o, incluso, ya no moverse en una dirección, sino permanecer, sedimentarse. No hay etapa posterior, superior y mejor, lo que hay es una serie de manifestaciones enmarcadas en la búsqueda de la densificación de las sociedades, locales, regionales y nacionales; así que todo aquello que le quite fuerza a lo social es inhumano, es decir, lo que no mejora el nivel de vida de las colectividades, su nivel educativo, su equilibrio con el entorno natural, su salud, su capacidad de organización y resistencia, etcétera.

Pero supongamos que estamos de acuerdo en que la densificación constituye, en efecto, la solera más poderosa de cualquier orden humano deseado. El problema es cómo densificar lo social en medio del poder demencial que han alcanzado el dinero y la política.

\section{Hacia una sociología de la convergencia}

Un posicionamiento social distinto plantearía las cosas de la siguiente manera: en las regiones de un país y en los espacios urbanos en donde 
se desatan los conflictos (pero preferentemente en la amplia gama de situaciones en donde no se desatan conflictos), tenemos que buscar formas (auto) organizativas que se propongan soluciones para mejorar la calidad de vida de los habitantes de esas regiones medias, generar consensos amplios orientados a esas soluciones (violencia-intra y extrafamiliar, degradación ambiental); trabajar ahí, obligar a que los presupuestos públicos y los apoyos privados de todo tipo vayan hacia ese nivel de lo social básico territorializado (exigir cuentas sobre los ingresos petroleros); nos referimos a espacios no tan pequeños y sin fuerza (como el barrio o la pequeña localidad), y no tan grandes que concentren los recursos y el poder en las burocracias estatales y delegacionales. Hay que orientar hacia ese nivel los saberes multidisciplinarios, las técnicas, las nuevas arquitecturas organizacionales que le dan poder a los hombres y a las mujeres en sus espacios de vida.

Lo que debemos preguntarnos, a partir de estas afirmaciones, es lo siguiente: para lograr cambiar la situación adversa y generadora de pobres y de infelices por la que atraviesa nuestra patria, ¿debería primero derrocarse a la clase capitalista y a sus aliados gubernamentales y estatales? o bien, para mejorar la calidad de vida de los mexicanos (que es a lo que todos aspiramos, presumo), es necesario, preferentemente, organizar y empoderar con cierta calma a los colectivos y buscar soluciones a sus ingentes necesidades, dirigir hacia ese nivel básico los recursos gubernamentales, lograr mejores concepciones y producir excelentes tecnologías; generar el asociativismo y la conciencia del entorno en los distintos espacios territoriales; buscar una vocación para esos espacios en medio del desmantelamiento provocado por las economías abiertas... para que desde lo social, así fortalecido y densificado, se haga posible tener un mejor control del entorno, un vigor y los instrumentos jurídicos y de correlación de fuerzas que permitan evitar que un Wal Mart se instale en el poblado o en la colonia, que un club de golf y su inmobiliaria acaparen las mejores tierras y los recursos freáticos, que una cadena hotelera destruya los manglares para enclavar uno de sus emporios y convertir a los lugareños en meseros, lancheros y taxistas mal pagados, evitar que sea expropiado a siete pesos cada 
metro de los ejidos para convertirlos en aeropuertos de a diez mil dólares el metro...

Pero trabajar paulatinamente para mejorar las condiciones de vida y reconstruir el entorno en una región media, la cuenca de un río por ejemplo, requiere de la concurrencia de muchos factores, actores y recursos: ¿los presidentes municipales son aliados o son adversarios de una reconstrucción llevada adelante desde un consejo ciudadano? ¿Los profesores de todos los niveles, incluido su sindicato que tanto daño ha hecho, son aliados potenciales o están corrompidos sin remedio? ¿Los empresarios, comerciantes y agricultores de la región son aliados para su reconstrucción? ¿Una empresa cervecera puede participar o es un enemigo intratable? ¿Es aceptable recibir de esa empresa diez millones de pesos para una planta potabilizadora que evite las enfermedades gastrointestinales que más afectan a la infancia en la región, o es cruzar las barricadas y dormir con el enemigo?

Tal planteamiento modifica la idea de que los universitarios vayan a dirigir al pueblo, como se creyó en los años setenta; las universidades, como hemos dicho, deben elaborar los diagnósticos, acompañar las soluciones, brindar apoyo y continuidad a los consejos ciudadanos; también dentro de la universidad hay que dar una larga batalla de convencimiento, calidad profesional y consensos en torno a su vocación y su eficacia social-regional, por evitar que sólo sea una máquina de cuadros para la burguesía. Eso se está haciendo en la UNAM, en la Universidad de Guadalajara, en la Autónoma de Nayarit: hoy con sus proyectos regionales, y la batalla está dada por seguir ampliando esas opciones y saberes, muchos de los cuales reciben gran apoyo en las facultades y en los rectorados, que no fue necesario derrocar (como llamó Marcos a hacerlo), para que fueran apoyados entusiastamente esos proyectos regionales, que se han propuesto, incluso, una articulación con los Caracoles, esas regiones medias tan ejemplares pero tan olvidadas por el discurso de la otra campaña zapatista.

Respaldemos lo anterior con el siguiente ejemplo: las llamadas Ciudades Blancas que se reparten en las riberas del bajo Guadalquivir en Andalucía, han elevado sustancialmente su calidad de vida en los 
últimos cuarenta años y han replegado a los tradicionales grupos dominantes y acaparadores de las fuentes de energía de esa cuenca gracias a un buen entendimiento de su vocación y su competitividad, centrada en el turismo, los servicios a él asociados, a un sistema educativo incluyente y de buen nivel para sus jóvenes, a la calidad en aumento de algunos productos primarios y a su transformación. Hay captación y buena distribución de energía externa, entre otras cosas, gracias a las divisas ahí derramadas. Es una región expuesta, como todas hoy, a la globalización, pero quizás en regiones como esa se ha sabido o se ha podido proteger las fuentes de generación de energía gracias a que sus habitantes, por las razones que se quiera, han tenido la fuerza para empujar a sus gobiernos a tomar medidas en tal dirección: es obvio que sus restaurantes, sus tiendas y sus hoteles no tienen la batalla perdida frente a Mac Donalds, Wal Mart o Sheraton.

Sin duda muchos problemas de la globalización se resienten ahí, como la caída salarial, la sustitución de empleados nacionales por extranjeros mal pagados, la competencia desventajosa con productos venidos de los campos del horror de la maquila mundial..., pero pensar que con violencia y destrucción debería hacerse frente a esas calamidades y no con un embarnecimiento y una activación del poder ciudadano, suena fuera de lugar. La pequeña burguesía restaurantera, hotelera y todos los marchantes de barrio de París y de muchas otras ciudades de Europa, siguen existiendo gracias a que tienen la fuerza social (densidad social) para hacer respetar sus intereses y su existencia frente a las grandes cadenas y gracias a que sus gobiernos departamentales o locales saben que enajenarse el apoyo de sus ciudadanos es el fin de su función político-administrativa por la vía de la activación y la movilización social.

\section{¿Contradicción o convergencia?}

El punto anterior nos permite regresar a la cuestión central en la temática que nos ocupa, es decir, en el tema de la construcción de sociedad, de cómo densificar a lo social. 
No cabe duda que en las sociedades aparecen constantemente la injusticia, la explotación y las amenazas a la soberanía; que esos hechos contundentes inducen al conflicto, al enfrentamiento de los contrarios, y que, según los postulados de la dialéctica, ese enfrentamiento conduciría, a su vez, a estadios nuevos, a etapas posteriores que, se ha asumido, pueden ser superiores o deberían ser superiores (la lucha de clases: el motor de la historia). Entonces el cambio y el mejoramiento social se producirían, según toda esta corriente de pensamiento y de acción, por la vía del conflicto, a lo que se agrega el ingrediente anticapitalista.

Cuando dos fuerzas se contraponen largamente, su energía, la energía generada en esa sociedad (o en ese espacio de la sociedad), se consume sin aprovechamiento ninguno. Tenemos así un campo en el que se genera energía y, dentro de él, fuerzas vectoriales. El objetivo sería evitar que esos vectores se anulen entre sí, enfrentados brutalmente o enfrentados largamente (¿empates catastróficos?), y más bien lograr que su direccionalidad se oriente en el sentido general de las fuerzas en ese campo social. Puede haber o no confrontación y puede haber confrontación aquí y en todas partes; lo que importa es la forma en que toma cauce esa confrontación. Es producto de un gran diseño y de una ingeniería humana el destrabamiento y la reorientación de esas fuerzas. En lo regional sería éste, sin duda, el trabajo de los agentes profesionales sociales y políticos que ahí participan.

Se entiende que estos planteamientos despierten en algunos lectores las viejas descalificaciones en torno al reformismo. Antonio Gramsci ${ }^{23}$ estableció la conocida diferencia entre la guerra de movimientos y la guerra de posiciones $y$, aunque recibió críticas, nunca fue severamente descalificado por las corrientes marxistas. Claro está que en la concepción gramsciana había una sucesión cronológica: en los países más desarrollados eran posicionamientos entre actores embarnecidos los que iban produciendo cambios paulatinos, mientras en los países menos desarrollados la dinámica social adoptaba las formas de la confrontación y el asalto al poder. Quizás debiéramos revisar nuestros instrumentos y preguntarnos si movimientos y posiciones (guerras de movimientos

${ }^{23}$ Antonio Gramsci, op. cit. 
y guerras de posiciones), no necesariamente tienen que hacer referencia a etapas que se suceden en el tiempo, sino a vías que se desenvuelven paralela y simultáneamente imperando una u otra de acuerdo con las características correspondientes a cada situación social. ¿Por qué la historia del Brasil parece ser más cercana a una estrategia de posiciones y la de México se corresponde mejor con los movimientos, la ruptura, la acumulación de fuerzas, el derrocamiento? 
CITAM Derechos Reservados.

La reproducción total o parcial de este artículo se podrá hacer si el ITAM otorga la autorización previamente por escrito. 